\title{
A importância dos livros didáticos para o ensino dos insetos
}

\section{The importance of didatic books in the teaching of insects}

Vitor Caveari Lage ${ }^{1}$

Wendel Mattos Pompilho ${ }^{2}$

Fernanda de Souza Silva ${ }^{3}$

\section{Resumo}

Este trabalho tem por objetivo discutir a importância do livro didático para o ensino de Ciências/Biologia abordando o tema Insetos. A Classe Insecta é constituída por animais cosmopolitas e com ampla diversidade biológica. Por tais motivos, os insetos são excelentes modelos didáticos e podem ser utilizados com uma ferramenta no processo de ensino/aprendizagem. Neste trabalho foi realizada uma análise, sobre o tema insetos, dos livros didáticos utilizados no ensino fundamental e médio. Foram analisados 21 livros didáticos onde foi possível observar uma breve abordagem do tema, porém foram discutidos os assuntos mais relevantes deste grupo.

Pavavras-chave: Insetos, Livros didáticos, Ensino-aprendizagem.

\section{Abstract}

This paper aims to discuss the importance of the textbook for the teaching of Science/Biology Insects addressing the issue. The Class Insecta is composed of Cosmopolitan animals with wide biological diversity. For these reasons, the insects are excellent teaching models and can be used with a tool in the teaching/learning. In this work an analysis was performed on the subject of insects, the textbooks used in elementary and high school. We analyzed 21 textbooks where it was possible to observe a brief overview of the topic, but discussed the most relevant topics in this group.

Keywords: Insects, Textbooks, Teaching-learning.

\footnotetext{
${ }^{1}$ Licenciado em Ciências Biológicas - Tutor CEDERJ/UENF

${ }^{2}$ Doutor em Bioquímica Agrícola - Tutor CEDERJ/UENF

${ }^{3}$ Mestre em Química Biológica - Professora da Faculdade Redentor Itaperuna - RJ
} 


\section{INTRODUÇÃO}

Os insetos são invertebrados pertencentes ao Filo ARTHROPODA. ARTHRO: significa articulação ou segmento. PODA: significa pé, pata ou apêndice. Ou seja, são animais invertebrados que possuem patas articuladas (GULLAN \& CRANSTON, 2008).

São os únicos invertebrados com capacidade de vôo e entre os artrópodes, apenas os insetos possuem o corpo dividido em cabeça, tórax e abdômen. A cabeça dos insetos é resultado da fusão de seis segmentos, apesar de não apresentar evidência de segmentação. De forma muito diversa e para atender aos diferentes hábitos de cada espécie, nela estão presentes os olhos compostos, os ocelos, um par de antenas sensoriais segmentadas e o aparelho bucal (VENTURA et al., 2004; GULLAN \& CRANSTON, 2008).

O tórax é composto por três segmentos: o protórax, o mesotórax e o metatórax. É o centro locomotor dos insetos, de onde partem os três pares de patas e as asas, quando presentes. As patas, na grande maioria das espécies são constituídas de seis segmentos: coxa basal, trocânter, fêmur, tíbia, tarso e pré-tarso onde se encontram garras ou unhas; são os principais órgãos de locomoção e apresentam grande variedade de adaptaçóes. As asas são compostas por duas camadas de cutícula membranosa, sustentadas por uma rede de nervuras, estão associadas ao mesotórax e ao metatórax, ocorrem mais comumente em dois pares. Assim como as patas, as asas dos insetos podem apresentar diversas modificaçôes: élitros, hemiélitros, tégminas e halteres (VENTURA et al., 2004; GULLAN \& CRANSTON, 2008).

O abdômen é o tagma da nutrição, nele também estão alojados os sistemas respiratório e reprodutor. É formado por um número variado de segmentos denominados urômeros. Os primeiros oito segmentos possuem, bilateralmente, aberturas externas do sistema traqueal, os espiráculos. Há urômeros modificados para excreção - o telso, e para reprodução - a terminália (VENTURA et al., 2004; GULLAN \& CRANSTON, 2008).

O revestimento externo ou exoesqueleto é formado por placas esclerosadas chamadas escleritos que se unem através de áreas de cutícula fina e membranosa. Isso garante mobilidade entre as partes. A constituição química dessa armadura é principalmente a quitina $\left(\mathrm{C}_{8} \mathrm{H}_{13} \mathrm{O}_{5} \mathrm{~N}\right) \mathrm{n}$, similar à celulose dos vegetais. Como o exoesqueleto não permite o crescimento do animal, ele é periodicamente trocado num processo chamado muda ou ecdise (VENTURA et al., 2004; GULLAN \& CRANSTON, 2008).

Quanto à diversidade e sucesso evolutivo dos insetos, Purves et al., (2005) afirmam que os insetos podem ter se originado a partir de ancestrais semelhantes a um centípede ainda no período Devoniano. Os ambientes terrestres invadi- dos pelos artrópodes eram como um novo planeta, um mundo ecológico com uma complexidade maior do que aquela dos mares dos quais eles vieram, mas contendo relativamente poucas espécies de animais. A evolução da capacidade de voar permitiu aos insetos fugir de predadores em potencial e ultrapassar fronteiras que, caso contrário, seriam intransponíveis - duas características altamente adaptativas. $\mathrm{O}$ número e a diversidade de espécies de insetos demonstram o sucesso supremo desse grupo animal altamente visível e dominante.

Os insetos apresentam um sucesso evolutivo único, trazendo consigo uma série de recordes tais como: habitam o planeta há milhóes de anos, são os únicos invertebrados que possuem asas e podem voar, adaptaram-se a quase todos os ambientes, reproduzem-se maciçamente, possuem grande força e resistência física proporcional e várias espécies desenvolveram e mantém organizações sociais complexas (GULLAN \& CRANSTON, 2008).

Macêdo et al., (2005) relatam que atualmente existem 950.000 espécies de insetos descritas, mas alerta para o fato de que esse número possa representar uma parcela muito pequena do total de insetos existentes, cujas estimativas podem variar entre 5.000 .000 e 30.000 .000 .

Pode-se perceber que esses animais são extremamente abundantes e diversificados, eles formam, atualmente, o grupo animal dominante na Terra, são mais numerosos que todos os outros animais, e são encontrados, praticamente, em todos os ecossistemas. Os insetos compreendem, aproximadamente, $89 \%$ das espécies pertencentes ao filo Arthropoda (MACÊDO et al., 2005).

Os hexápodes apresentam uma enorme importância ecológica, econômica e médica.

Plantas e insetos interagem entre si de certas formas que são vitais para ambos; as mais importantes são a herbivoria e a polinização. Nessas relaçôes, as plantas e os insetos evoluem em resposta a adaptaçóes apresentadas pelo outro em um processo gradual denominado coevolução e cada um deles é uma força seletiva importante para a evolução do outro. Os insetos polinizam quase $70 \%$ das espécies que produzem flores, e a grande diversidade da estrutura floral reflete amplamente as adaptaçóes para facilitar a polinização. Abelhas, vespas, borboletas, mariposas e moscas são os principais insetos polinizadores (RUPPERT, et al.,2005).

Purves et al., (2005) afirmam que os insetos são encontrados em praticamente todos os habitats terrestres e de água doce, e eles se alimentam de quase todas as espécies de plantas, além de muitas espécies animais. Alguns são endoparasitas de plantas e de animais; outros sugam o sangue dos seus hospedeiros ou consomem os tecidos da superfície do corpo desses.

Mesmo com vasta diversidade biológica e popularidade diversas pessoas, incluindo-se neste grupo alunos do Ensino Fundamental e Médio, trazem consigo a concep- 
ção de que animais considerados nocivos ou perigosos estáo agrupados na classe dos insetos, desta forma acabam por confundir aranhas, lacraias e carrapatos, além de exemplares de classes mais distantes, com insetos (MACÊDO et. $a l, 2005)$. Entretanto, durante o ensino/aprendizagem de Ciências e Biologia, a classe dos insetos permite aos professores oferecer aos alunos inúmeras oportunidades na construção de conceitos concretos sobre tais animais (BATISTA \& COSTA NETO, 2008).

Trabalhar com os insetos em sala de aula traz não só a oportunidade de acabar com esse preconceito, mas também a possibilidade de utilizá-los como ferramenta pedagógica para o desenvolvimento de habilidades como observaçáo, argumentação, postura crítica, curiosidade, criatividade e clareza de expressão, tão desejáveis no ambiente escolar.

Como relatado anteriormente, esses animais são extremamente abundantes e diversificados, e podem ser encontrados em qualquer lugar e em quase todas as épocas do ano, fato considerado como forte indicativo de que as relaçôes que a espécie humana estabelece com os insetos são múltiplas e, ao mesmo tempo, ambíguas (BATISTA \& COSTA NETO, 2008).

Nas diversas áreas do conhecimento e artes, tais como literatura, cinema e música, pode-se sentir a presença e a influência dos insetos (BATISTA \& COSTA NETO, 2008). Segundo as tendências mais modernas da educação, os alunos já chegam à sala de aula trazendo conhecimentos prévios, portanto, eles já sabem muitas coisas sobre os insetos. Neste sentido, é importante que os insetos estejam mais ativamente presentes nas salas de aulas, uma vez que muitos conceitos básicos podem ser ensinados através da observação dos mesmos.

Segundo Batista \& Costa Neto (2008) muitas vezes, o ensino sobre insetos em Ciências e Biologia não é conduzido de forma apropriada devido às atitudes, instruçóes e experiências tanto dos professores quanto dos alunos. No mundo natural, os insetos (e demais artrópodes e alguns invertebrados) que mais notamos são aqueles associados com desconforto e perigo. Tal atitude é freqüentemente transmitida pela mídia, que nos ensina que esses organismos são perigosos, nojentos, causadores de doenças e daninhos às plantaçóes.

Diante do exposto, torna-se essencial que os professores saibam escolher recursos literários que abordem os insetos, contemplando a realidade sócio-cultural dos alunos, fazendo um contraponto entre os contextos científico e didático. $\mathrm{O}$ recurso literário amplamente utilizado pelos professores é o livro didático.

Qualquer livro sempre traz uma mensagem, um conjunto de informaçóes que não estão desprovidos de um contexto e de uma ideologia subjacente. Com o livro didático não é diferente. Vários autores (FLEURY, 1961; DIB, 2004; PFROMM NETO et al., 1974; OLIVEIRA et al.,
1984; COSTA, 1998) reforçam a idéia de que muitas características do livro didático estão intrinsecamente relacionadas ao seu período histórico, a uma vertente metodológica da época e respondem aos objetivos da educação propostos pelas entidades oficiais de ensino.

O livro didático assume uma importância muito grande no processo de ensino/aprendizagem, pois representa um, senão o único, instrumento significativo ao qual muitos alunos e professores têm acesso. Segundo Gérard \& Roegiers (1998), a função do livro está direcionada para a aprendizagem escolar e para estabelecer uma ligação entre as aprendizagens escolares e a vida cotidiana e profissional. Contudo, o mundo impóe ao livro didático, com os seus avanços tecnológicos e sociais, uma competição acirrada em relação às informaçóes, gerando novas funçóes para este instrumento. De acordo com Fleury (1961), o livro didático tinha a função de auxiliar ao professor. Não há referências em relaçáo à formação da cidadania e do aluno pesquisador, apenas no sentido de ajudá-lo a dosar o que seria ensinado em sala de aula, seguir orientaçóes metodológicas comprovadamente eficazes, já testadas por mestres renomados e, finalmente, dar condiçóes aos alunos e professores de terem contato com fotos, gráficos, retratos e ou obras de difícil acesso. Ou seja, o livro didático é um material de compilação de dados para consulta e estudo. Hoje, acredita-se na ampliação dessas funções. O Ministério da Educação e Cultura - MEC, no documento que define os critérios de avaliação dos livros didáticos, destaca funçôes como a internalização e domínio da linguagem, nos seus diversos gêneros, como alfabetização, linguagem matemática, manual de software, línguas estrangeiras.

Outra função apresentada é a construção do conhecimento por meio do processamento do texto impresso, com ampliação e aprofundamento das diversas áreas do conhecimento (BRASIL, 1994).

Neste contexto, o presente artigo tem por objetivo analisar livros didáticos em relação a abordagem com o tema "Insetos".

\section{METODOLOGIA}

\section{Análise dos Livros didáticos}

Os livros foram analisados com o propósito de verificar quantitativamente as páginas dedicadas ao tema insetos em relação ao total de páginas relativas ao Reino Animal. Dessa forma buscou-se os percentuais de páginas dos livros didáticos adotados em escolas públicas no município de Miracema-RJ. 
Para efeito comparativo foi analisado os percentuais de páginas dedicadas aos Mamíferos e as Aves, também, em relação ao total de páginas sobre o Reino Animal.

Complementando a análise, observou-se nos livros, os assuntos abordados nos capítulos destinados ao tema insetos quanto a sua presença ou ausência: Morfo-fisiologia, Desenvolvimento, Classificação, Importância Ecológica, Aspectos Negativos e Atividades sobre o tema insetos.

A análise foi feita com 12 livros de Ciências da 6a série do Ensino Fundamental e com 9 livros de Biologia do Ensino Médio. Abaixo a relação dos livros.

\section{Relação de Livros de Ciências da $6^{a}$ Série do Ensino Fundamental Analisados}

1. Albino Fonseca. Ciências: os seres vivos. 6a série. Editora IBEP. 2004.

2. Carlos Barros e Wilson \& Roberto Paulino. Ciências: os seres vivos 67.ed. Ática 1999.

3. César da Silva Júnior, Sezar Sasson e Paulo Sérgio Bedaque Sanches. Ciências: entendendo a natureza: os seres vivos no ambiente, 6a série. 20.ed. Saraiva. 2005.

4. Daniel Cruz. Tudo é Ciências: seres vivos. 6a série. Ática 2007.

5. Demétrio Gowdak e duardo Martins. Novo Pensar: com atualizaçóes: seres vivos, 6a série. FTD 2006.

6. Fernando Gewandsznajder. Ciências: a vida na terra $6^{\mathrm{a}}$ série. 2.ed. Ática. 2005.

7. José Trivellato et al.Ciências natureza \& cotidiano: criatividade, pesquisa, conhecimento. FTD 2004.

8. Maria de la Luz M.Costa e Magaly Terezinha dos Santos. Vivendo Ciências 6a série. FTD. 1999.

9. Neide Simóes de Mattos e Dinorah Polleto Porto. Projeto Radix: ciências, 6a série. Scipione. 2005.

10. Nélio Bizzo e Marcelo Jordão. Ciências BJ, 6a série. Ed. Do Brasil. 2005.

11. Paulo Maurício Silva e S. R. Fontinha Ciências: a biodiversidade 6a série 3.ed. Cia Ed. Nacional 2001.
12. Sônia Lopes e Ana Machado. Ciências: a vida $6^{\mathrm{a}}$ série. Atual. 1996.

\section{Relação de Livros de Biologia do Ensino Médio Analisados}

1. Albino Fonseca Biologia: curso completo. IBEP. 2000.

2. César da Silva Júnior e Sezar Sasson Biologia - volume único 2.ed. Saraiva. 1999.

3. César da Silva Júnior e Sezar Sasson. Biologia - volume 2 - 2a série - seres vivos: estrutura e função. Saraiva. 2005.

4. Demétrio Gowdak e Neide S. de Mattos. Biologia: volume único. FTD. 1991.

5. J. Laurence Biologia: ensino médio: volume único 1 . ed. Nova Geração. 2005.

6. José Luís Soares Biologia: volume único. Scipione. 1997.

7. José Luís Soares. Biologia - vol III - seres vivos - evolução - ecologia. 2. ed. Scipione. 1993.

8. José Mariano Amabis e Gilberto Rodrigues Martho. Biologia: biologia dos organismos, volume 2 - A diversidade dos seres vivos. 2.ed. Moderna. 2004.

9. Sônia Godoy Bueno Carvalho Lopes. Bio 2: seres vivos 11.ed. Saraiva. 1994.

\section{RESULTADOS E DISCUSSÃO}

Considerando o quantitativo de animais descritos atualmente, para cada uma das classes (insetos, mamíferos e aves) nota-se que os insetos são inquestionavelmente mais numerosos. Entretanto, esse fato não é considerado nos livros didáticos analisados, pois o percentual de páginas dedicadas ao estudo dos Insetos é pequeno quando comparado aos valores percentuais dedicados a Mamíferos e Aves (Tabela 1).

Na tabela 1 é possível observar o resultado da análise dos livros de $6^{\mathrm{a}}$ série do Ensino Fundamental e Biologia do Ensino Médio, em relação ao total de páginas destinadas a abordar Reino Animal.

Tabela 1: Relação entre as páginas destinadas às classes de insetos, mamíferos e aves e o total de páginas que abordam o Reino Animal em 12 livros de Ciências da 6a série do Ensino Fundamental e Biologia do Ensino Médio.

\begin{tabular}{|c|c|c|}
\hline \multirow{2}{*}{ Classes } & \multicolumn{2}{|c|}{ Percentual de Páginas } \\
\cline { 2 - 3 } & Ciências & Biologia \\
\hline Insetos & 6,2 & 6,4 \\
\hline Mamíferos & 10,9 & 5,9 \\
\hline Aves & 8,9 & 4,1 \\
\hline
\end{tabular}


Quando comparado a abordagem dos livros de nível Fundamental e Médio não foi observado um aumento no percentual de páginas dedicadas aos insetos, no entanto, é notória uma queda, aproximada, de 50\% para as classes dos mamíferos e aves. A pequena abordagem da Classe Insecta pelos livros didáticos revela a pouca importância que é dada a esse grupo nos ensinos Fundamental e Médio. Desta forma é possível que concepçóes incorretas a respeito dos insetos sejam estabelecidas pelos estudantes.
Complementando a análise, a Tabela 2 revela os assuntos abordados nos capítulos destinados ao tema insetos. Nota-se que a maioria dos livros analisados traz em seus capítulos os itens Morfo-fisiologia, Desenvolvimento, Classificação, Importância Ecológica, Aspectos Negativos e Atividades sobre o tema insetos. O item Classificação aparece em 50\% dos livros de $6^{\mathrm{a}}$ série, bem como nos livros de Biologia do Ensino Médio, a Importância Ecológica foi detectado em $56 \%$ dos livros analisados.

\begin{tabular}{|c|c|c|}
\hline \multicolumn{2}{|c|}{$\begin{array}{c}\text { Tabela 2: Assuntos que os livros de Ciências da 6a série do Ensino Fundamental e } \\
\text { de Biologia do Ensino Médio abordam dentro do capítulo destinado ao tema insetos. }\end{array}$} \\
\hline \multirow{2}{*}{ Assuntos } & Ciências & Percentual de Livros \\
\cline { 2 - 3 } & $100 \%$ & $100 \%$ \\
\hline Morfo-Fisiologia & $100 \%$ & $89 \%$ \\
\hline Desenvolvimento & $50 \%$ & $89 \%$ \\
\hline Classificação & $83 \%$ & $56 \%$ \\
\hline Importância Ecológica & $92 \%$ & $89 \%$ \\
\hline Aspectos Negativos & $83 \%$ & $100 \%$ \\
\hline Atividades & & \\
\hline
\end{tabular}

Na tabela 2, observamos que a Importância Ecológica dos insetos foi o assunto com menor abordagem pelos autores dos livros analisados, neste sentido faz necessário ampliar essa discussão. Os insetos estão diretamente envolvidos em interaçôes ecológicas, as quais oferecem benefícios para o homem, podemos citar: polinização de inúmeras espécies vegetais; controle biológico de pragas agrícolas; produção de seda pelo bicho da seda (Bombyx mori) e mel pelas abelhas (Apis mellifera). Por outro lado, podem causar danos à saúde humana e prejuízo econômico, pois existem espécies que atuam como vetores de doenças (ex.: Aedes aegypti - vetor da dengue e febre; Anopheles Darlingi - transmissor da malária; Panstrongylus megistus e Triatoma infestans - vetor da doença de Chagas) e espécies que devastam culturas agrícolas (ex. broca da cana de açúcar - Diatraea saccharalis; lagarta desfolhadora dos citros - Heraclides thoas brasiliensis; lagarta da espiga do milho - Helicoverpa zea) (GALLO, et al., 2002; VENTURA, et al., 2004; GULLAN \& CRANSTON, 2008).

O livro didático adquire a função de orientar o processo de aprendizagem. Neste sentido, é importante que os temas abordados nos livros sejam claros, e coerentes com o nível de conhecimento e série dos alunos. Todos os livros analisados neste trabalho foram satisfatórios ao abordarem o tema insetos, pois foram discutidos todos os aspectos importantes deste grupo (Tabela 2), mesmo dedicando poucas páginas em relação ao total de páginas dedicas ao Reino Animal (Tabela 1).
Os livros analisados, assim como vários Livros Didáticos, apresentam pontos negativos. Um deles é tratar o conhecimento científico como pronto, acabado, atemporal e elaborado por cientistas privilegiados, alijados de um contexto histórico, cultural, ideológico e ético. Dessa forma, caracteriza uma prática metodológica por meio da qual o aluno se encontra como ser passivo, depositário de informaçôes desconexas e descontextualizadas. Segundo Vasconcelos \& Souto (2003) em Ciências e, especificamente, em Biologia, o livro didático deve fazer compreender como o conhecimento científico é produzido e estruturado além de propiciar uma visão da realidade em termos filosóficos e estéticos da realidade.

Geralmente, percebe-se que os livros didáticos não incorporam os fundamentos teórico-metodológicos dos PCN de Ciências (BRASIL. 1997). Muitos livros didáticos tentam apropriar-se de avanços educacionais e fundamentos teóricos, mas a implementação dessas idéias não se efetiva nos textos nem nas atividades propostas, embora possam aparecer nas orientaçóes metodológicas da obra. É como se estivessem apenas "dourando a pílula". As ideologias presentes nos livros didáticos de Ciências acabam por produzir alunos com uma visão deturpada das Ciências.

O livro, desde que foi inventado, serviu como veículo de acumulação, geração e transmissão de informação. Atualmente, com as novas vertentes de ensino, espera-se que ele ajude a preparar os educandos para a vida, para aprender a aprender, para a formação da cidadania. 


\section{CONCLUSÃo}

Os livros analisados abordaram os assuntos mais relevantes sobre a classe dos insetos, porém ficou constatada a necessidade de ampliar a discussão sobre este grupo, tendo em vista sua vasta diversidade e importância ecológica.

\section{REFERÊNCIAS}

29. BATISTA, G. C. S.; COSTA NETO, E. M. Conhecendo os insetos na escola. Disponível em: <http//:www. mundoacademico.unifap.br.>. Acesso em: 27 abr. 2012.

30. BRASIL. MEC. Definição de critérios para avaliação dos livros didáticos. Brasília, 1994.

31. BRASIL. Secretaria de Educação Fundamental. Parâmetros curriculares nacionais: ciências naturais/Secretaria de Educação Fundamental. - Brasília: MEC/SEF, 1997. 136p.

32. COSTA, R. C. Os obstáculos epistemológicos de Bachelard e o ensino de Ciências. Caderno Educacional. FAE/UF Pelotas, n. 11, p 153-167, julho/dez, 1998.

33. DIB, S. M. F. Análise de imagens em livros didáticos de Química: Um caminho para a comunicação de conceitos científicos. 2004. 149f. Dissertação (Mestrado em Educação)- Faculdade de Educação, Universidade Católica de Brasília, Brasília. 2004.

34. FLEURY, R. S. Livro didático. Revista Brasileira de estudos Pedagógicos, Brasília, v. 35, n. 82, abril/jun. 1961.

35. GALLO, D.; NAKANO, O.; SILVEIRA NETO, S.; CARVALHO, R. P. L.; BATISTA, G. C.; BERTI FILHO, E.; PARRA, J. R. P.; ZUCCHI, R. A.; ALVES, S. B.; VENDRAMIN, J. D.; MARCHINI, L. C.; LOPES, J. R. S.; OMOTO, C. Entomologia agrícola. Piracicaba: FEALQ, 2002. 920 p.
36. GÉRARD, F. M; ROEGIERS, X. Conceber e avaliar manuais escolares. Porto: Porto Ed. 1998. 344 p.

37. GULLAN, P.J. \& CRANSTON, P.S. 2008. Os Insetos: Um resumo de Entomologia. 3a. ed. São Paulo, Roca, 456 p.

38. MACÊDO, M. V.; FLINTE, V.; GRENHAS, V. Insetos na Educação. v. 1. Rio de Janeiro: Fundação CECIERJ, 2005.

39. Oliveira, J. B. A; GUimarÁES, S. D. P; BOMÉNY, H. M. B. A política do livro didático. São Paulo: Ed. Summus e Unicamp, 1984.

40. PFROMM NETO, S; DIB, C; ROSAMILHA, N. Livro na educação. Rio de Janeiro: Primor, 1974.

41. PURVES, W. K.; SADAVA, D.; ORIANS, G. H.; HELLER, H. C. Vida: a ciência da biologia. Ana Paula Somer Vinagre [et al.] (trad.). 6. ed. vol.2. Porto Alegre: Artmed, 2005.

42. RUPPERT, E. E.; FOX, R. S.; BARNES, R. D. Zoologia dos Invertebrados: uma abordagem funcional-evolutiva. São Paulo: Roca, 2005.

43. VASCONCELOS, S. D; SOUTO, E. O livro didático de Ciências no ensino médio fundamental - Uma proposta de critérios para análise do conteúdo zoológico. Ciência e Educação, São Paulo, v. 9, n. 1, p. 93-104, 2003.

44. VENTURA, C. R. R.; MELLO-PATIU, C. A.; MEJDALANI, G. Diversidade Biológica dos Protostomados. 2. ed. v.2. Rio de Janeiro: Fundação CECIERJ, 2004.
Endereço para Correspondência:

Wendel Mattos Pompilho -wendelpompilho@yahoo.com.br UNIG Campus V Av. Cel. Macário, no 2009 - Retiro do Muriaé Itaperuna - RJ

CEP: 28330-000 